\title{
Sensitivity analysis of surface runoff generation in urban flood forecasting
}

\author{
N. E. Simões, J. P. Leitão, Č. Maksimović, A. Sá Marques and R. Pina
}

\footnotetext{
$\overline{\text { ABSTRACT }}$

Reliable flood forecasting requires hydraulic models capable to estimate pluvial flooding fast enough in order to enable successful operational responses. Increased computational speed can be achieved by using a 1D/1D model, since 2D models are too computationally demanding. Further changes can be made by simplifying 1D network models, removing and by changing some secondary elements. The Urban Water Research Group (UWRG) of Imperial College London developed a tool that automatically analyses, quantifies and generates 1D overland flow network. The overland flow network features (ponds and flow pathways) generated by this methodology are dependent on the number of sewer network manholes and sewer inlets, as some of the overland flow pathways start at manholes (or sewer inlets) locations. Thus, if a simplified version of the sewer network has less manholes (or sewer inlets) than the original one, the overland flow network will be consequently different. This paper compares different overland flow networks generated with different levels of sewer network skeletonisation. Sensitivity analysis is carried out in one catchment area in Coimbra, Portugal, in order to evaluate overland flow network characteristics.

Key words | dual drainage, flood forecasting, simplification of sewer and overland networks

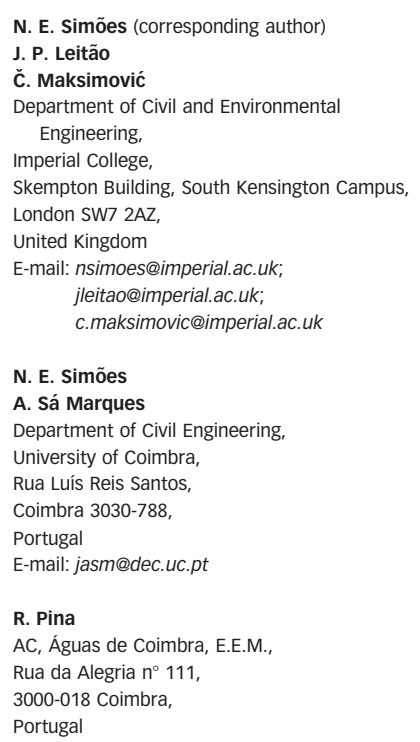

